\title{
Metodologia para avaliação dos consórcios de resíduos sólidos urbanos em Minas Gerais
}

\author{
Methodology for assessment of consortia of municipal solid waste in Minas Gerais
}

Cynthia Fantoni Alves Ferreira', José Fernando Thomé Jucá2

\begin{abstract}
RESUMO
Um dos grandes problemas enfrentados atualmente nas áreas urbanizadas é a disposição final dos resíduos sólidos urbanos (RSU). Essa problemática contempla todo o processo de produção do resíduo, seu descarte, acondicionamento, coleta, transporte, tratamento e disposição final, bem como o padrão de consumo contemporâneo. Os estudos previstos no âmbito desta pesquisa têm como objetivos fortalecer os consórcios, ampliando a sua importância, representatividade e abrangência, favorecer a integração com as entidades e instituições relacionadas ao tema, aumentando as discussões no âmbito regional, e avaliar as rotas tecnológicas aplicadas ao tratamento dos resíduos dos municípios integrantes dos consórcios. Este artigo apresenta uma metodologia para avaliação dos consórcios de RSU em Minas Gerais como uma alternativa no campo da gestão de RSU, para fins de otimização de recursos e gestão de serviços que fazem a gestão de RSU viável para todos. Nesse sentido, é realizada uma análise das rotas tecnológicas de RSU, avaliando-se a eficácia da tecnologia utilizada nos municípios com base nos consórcios já formados e nas propostas dos Arranjos Territoriais Ótimos (ATOs) de Minas Gerais.
\end{abstract}

Palavras-chave: consórcios; resíduos sólidos urbanos; rotas tecnológicas.

\begin{abstract}
One of the major problems currently faced in urbanized areas is the final disposal of the municipal solid waste (MSW) generated. The problem, however, is not restricted only to its final disposal, but instead encompasses the whole process of the production of waste, its discarding, storage, collection, transportation, treatment, and final disposal, as well as current consumption patterns. The studies planned under this research aim to strengthen consortia, increasing their importance, representativeness, and scope, and also encourage the integration with entities and institutions involved in the field, fostering discussions at the regional level and evaluate technological routes applied by the consortia. This article presents the methodology for assessment of Consortia of municipal solid waste in the state of Minas Gerais as an alternative in the field of MSW management, for the purposes of scale increase, resource optimization, and operation of services making MSW management viable for everyone. Then, it does an analysis of the MSW technological routes, evaluating the effectiveness of the technology used in the municipalities taking into account of already formed consortia and proposals in Minas Gerais Optimal Territorial Arrangements (ATOs).
\end{abstract} Keywords: consortia; municipal solid waste; technological routes.

\section{INTRODUÇÃO}

Os consórcios têm sido vistos como uma alternativa no campo da gestão integrada de resíduos sólidos urbanos (GIRSU), tanto para os municípios que buscam alternativas de local para a disposição final como para o ganho de escala, otimizando recursos e tratamento dos resíduos, além de atenderem a um maior número de municípios e viabilizarem a gestão dos resíduos sólidos urbanos (RSU) para todos.

Destacam-se os instrumentos legais, como a Lei no 18.031/2009, que estabelece a Política Estadual de Resíduos Sólidos de Minas Gerais (MINAS GERAIS, 2009) e, mais recentemente, a Lei $n^{\circ}$ 12.305/2010, que criou a Política Nacional dos Resíduos Sólidos (BRASIL, 2010), que versa sobre as diretrizes relativas à gestão integrada e ao gerenciamento de resíduos sólidos (incluídos os perigosos), às responsabilidades dos geradores e do poder público quanto à adoção, ao desenvolvimento e ao aprimoramento de tecnologias limpas e aos instrumentos econômicos aplicáveis.

O estudo preliminar do Ministério do Meio Ambiente (MMA) para constituição de futuros consórcios públicos para gestão de resíduos sólidos, nos moldes das Leis n 11.107/2005 e n 11.445/2007 (BRASIL, 2005; 2007), é o marco referencial para uma visão integrada à respectiva legislação estadual e à Política Nacional de Resíduos Sólidos (PNRS). A consolidação dos consórcios públicos regionais como modelos de gestão de resíduos sólidos é uma estratégia do governo federal, que vem desenvolvendo ações, principalmente, por meio do MMA. A sustentabilidade dos consórcios públicos centra-se em um modelo que privilegia a redução da geração e da disposição final de resíduos, fomenta a utilização de aterros sanitários em uma escala otimizada, com a inclusão 口-

'Pesquisadora Pós-Doutora do Conselho Nacional de Desenvolvimento Científico e Tecnológico (CNPq). Doutora em Meio Ambiente, Saneamento e Recursos Hídricos do Departamento de Engenharia Sanitária e Ambiental da Universidade Federal de Minas Gerais (UFMG) - Belo Horizonte (MG), Brasil. 2Professor Titular da Universidade Federal de Pernambuco (UFPE). Pesquisador do CNPq - Recife (PE), Brasil.

Endereço para correspondência: Cynthia Fantoni Alves Ferreira - Rua Jaime Gomes, 159 - Floresta - 31015-240 - Belo Horizonte (MG), Brasil - E-mail: cynthia.ambientacy@gmail.com Recebido: 23/03/15 - Aceito: 29/06/16 - Reg. ABES: 147551 
dos catadores e a promoção de ações de geração de trabalho e renda, e, ainda, é replicável em outras regiões, inclusive da América Latina.

Nesse contexto, destaca-se também o Plano Preliminar de Regionalização para Gestão Integrada de Resíduos Sólidos Urbanos de Minas Gerais (PRE-RSU). Os planos constituem uma base de dados técnicos primários e secundários sobre os aspectos socioeconômico, logístico e ambiental, e da própria gestão de resíduos utilizados, para sugerir configurações para a regionalização da gestão de RSU na forma de agrupamentos e Arranjos Territoriais Ótimos (ATOs). O agrupamento é a unidade de análise básica que prevê a possibilidade de compartilhamento de uma unidade de manejo e destinação tendo como critério básico a distância referencial entre os municípios $(30 \mathrm{~km})$. Já o ATO é o arranjo maior que garantirá a viabilidade e a sustentabilidade da regionalização, considerando, principalmente, as fragilidades socioeconômicas que impedem que cada município desempenhe adequadamente as atividades de gestão de resíduos na forma individualizada (FERREIRA et al., 2010).

Ainda segundo Ferreira et al. (2010), foram utilizados alguns critérios para a formação dos 51 ATOs do Estado de Minas Gerais, como, por exemplo: pelo menos uma cidade polo com, preferencialmente, uma população de, no mínimo, 100 mil habitantes. A modelagem desses ATOs sugere um referencial técnico para a constituição de consórcios intermunicipais destinados à GIRSU.

A formação de consórcios públicos intermunicipais para a GIRSU é incentivada pelo governo mineiro, como explicitado na Deliberação Normativa no 118/2008, do Conselho de Política Ambiental (COPAM), e na Lei Estadual no 18.031/2009, que define a Política Estadual de GIRSU (MINAS GERAIS, 2008; 2009). De acordo com a Lei, as ações do consórcio devem estar descritas no Protocolo de Intenções e, após aprovação em cada Câmara Municipal, no Contrato do Consórcio, que deve conter os direitos e deveres de cada participante, além das formas de regulação, fiscalização e distribuição de custos. Cada ente federativo pode participar de apenas um consórcio para a execução de uma determinada atividade.

O Estado de Minas Gerais está inserido no Núcleo Regional Sudeste do Projeto GRS/FADE/UFPE/BNDES, desenvolvido com o objetivo de mapear os dados qualiquantitativos dos resíduos sólidos, as rotas tecnológicas utilizadas, bem como os principais tipos de tratamento e destinação final, e analisar as diversas tecnologias de tratamento e disposição final de RSU no Brasil, na Europa, no Japão e nos Estados Unidos da América (EUA) (GRS/UFPE, 2014).

Em relação às tecnologias utilizadas em Minas Gerais, os aterros sanitários, unidades regularizadas de triagem e compostagem, atendem a cerca de $48,7 \%$ da população urbana. As Unidades de Triagem e Compostagem (UTCs) são empregadas no Estado principalmente para os municípios de pequeno porte. Conforme dados disponíveis em 2012, Minas Gerais apresentava 122 UTCs regularizadas e 24 não regularizadas. Os aterros controlados correspondem a 16,2\% (FEAM, 2012). Assim, pode-se dizer que os aterros sanitários aparecem como alternativa para disposição final adequada dos RSU de municípios de maior porte populacional, podendo ou não apresentar unidades de triagem. As UTCs são mais empregadas nos municípios de menor porte, nos quais os resíduos potencialmente recicláveis são comercializados e os potencialmente compostáveis são transformados em compostos orgânicos que podem ser reaproveitados em parques, praças e na própria área da unidade.

No que se refere ao controle dos serviços relativos aos resíduos sólidos, o planejamento de um consórcio não exclui a competência do Estado, mas refere-se a uma gestão mais descentralizada, visto que ele exerce o controle e a fiscalização de natureza ambiental sobre os resíduos sólidos.

\section{MATERIAL E MÉTODOS}

A pesquisa foi desenvolvida em duas etapas, conforme apresentado na Figura 1.

\section{Avaliação dos arranjos técnicos, institucionais e legais dos consórcios em operação}

Segundo a Secretaria do Estado de Desenvolvimento Regional e Política Urbana (SEDRU, 2013), os consórcios em “operação" são aqueles que já possuem em funcionamento empreendimento para tratamento e/ou destinação final de resíduos sólidos com aterro sanitário regional. Durante os meses de janeiro e fevereiro de 2014, foram realizadas entrevistas semiestruturadas durante as visitas técnicas in loco na sede dos consórcios (Tabela 1).

Para a coleta de dados primários junto aos representantes dos consórcios, foram realizadas entrevistas semiestruturadas apoiadas por dois formulários: 1 - estrutura organizacional e 2 - caracterização dos RSU, do tratamento e da disposição final, elaborados pelo pesquisador para avaliar o sistema de manejo, tratamento e destinação final e os aspectos institucionais e legais para:

- $\quad$ apuração da existência de normas sobre a coleta, tratamento, disposição e atividades congêneres relacionadas a resíduos sólidos;

- levantamento e análise de documentos institucionais, técnicos e planos existentes na área de abrangência sobre resíduos sólidos e demais temas relacionados como Planos Diretores, Planos de Saneamento Básico de Gestão de Resíduos Sólidos;

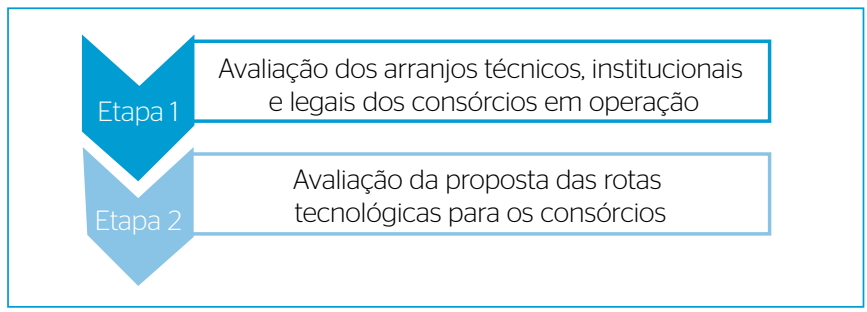

Figura 1 - Etapas metodológicas. 
- levantamento de dados como caracterização dos RSU, coleta seletiva e sistema de tratamento e disposição final dos municípios dos consórcios.

A Tabela 1 apresenta de forma sucinta os cinco consórcios “em operação" avaliados na pesquisa.

Tabela 1 - Situação dos consórcios “em operação” em Minas Gerais.

\begin{tabular}{|c|c|c|c|}
\hline Consórcios & $\begin{array}{c}\text { Situação/tecnologias } \\
\text { utilizadas }\end{array}$ & $\begin{array}{c}\text { Municípios } \\
\text { aderidos/ } \\
\text { população (em } \\
\text { habitantes) }\end{array}$ & $\begin{array}{c}\text { Área de } \\
\text { atuação/ } \\
\text { natureza } \\
\text { jurídica }\end{array}$ \\
\hline CIMASAS & $\begin{array}{l}\text { Consórcio } \\
\text { constituído com } \\
\text { aterro sanitário em } \\
\text { operação. }\end{array}$ & $\begin{array}{c}6 \text { municípios } \\
118.411\end{array}$ & $\begin{array}{l}\text { Específico: } \\
\text { gestão e } \\
\text { disposição } \\
\text { final de RSU/ } \\
\text { associação } \\
\text { pública. }\end{array}$ \\
\hline ECOTRES & $\begin{array}{l}\text { Consórcio } \\
\text { constituído com } \\
\text { aterro sanitário em } \\
\text { operação; } \\
\text { Unidade de triagem } \\
\text { (implantação); } \\
\text { Unidade de } \\
\text { compostagem } \\
\text { (implantação). }\end{array}$ & $\begin{array}{c}3 \text { municípios } \\
200.299\end{array}$ & $\begin{array}{l}\text { Específico: } \\
\text { gestão e } \\
\text { disposição } \\
\text { final de RSU/ } \\
\text { associação } \\
\text { pública. }\end{array}$ \\
\hline CPGRS & $\begin{array}{c}\text { Consórcio constituído } \\
\text { com aterro sanitário } \\
\text { em operação }\end{array}$ & $\begin{array}{l}5 \text { municípios } \\
130.552\end{array}$ & $\begin{array}{l}\text { Específico: } \\
\text { gestão e } \\
\text { disposição } \\
\text { final de RSU/ } \\
\text { associação } \\
\text { pública. }\end{array}$ \\
\hline CORESAB & $\begin{array}{c}\text { Consórcio } \\
\text { constituído com } \\
\text { aterro sanitário em } \\
\text { operação; } \\
\text { Aterro sanitário } \\
\text { (7 previstos); } \\
\text { Aterro sanitário de } \\
\text { pequeno porte } \\
\text { (2 previstos); } \\
\text { Galpões de triagem } \\
\text { (7 previstos); } \\
\text { Unidades de } \\
\text { compostagem } \\
\text { (5 previstos). }\end{array}$ & $\begin{array}{c}18 \text { municípios } \\
239.948\end{array}$ & $\begin{array}{l}\text { Multissetorial } \\
\text { Saneamento } \\
\text { em geral } \\
\text { e gestão e } \\
\text { disposição } \\
\text { final de } \\
\text { RSU e RSS/ } \\
\text { associação } \\
\text { pública. }\end{array}$ \\
\hline $\begin{array}{l}\text { Consórcio } \\
\text { Intermunicipal } \\
\text { de Reciclagem e } \\
\text { Compostagem } \\
\text { do Lixo }\end{array}$ & $\begin{array}{c}\text { Consórcio } \\
\text { constituído com } \\
\text { usina de triagem e } \\
\text { compostagem em } \\
\text { operação. }\end{array}$ & $\begin{array}{c}5 \text { municípios } \\
16.222\end{array}$ & $\begin{array}{c}\text { Específico: } \\
\text { gestão e } \\
\text { disposição } \\
\text { final de RSU/ } \\
\text { associação } \\
\text { privada } \\
\text { (em mudança } \\
\text { para } \\
\text { associação } \\
\text { pública). }\end{array}$ \\
\hline
\end{tabular}

Fonte: SEDRU, 2013

CIMASAS: Consórcio Intermunicipal de municípios do Alto Sapucaí para Aterro Sanitário; ECOTRES: Consórcio Público Intermunicipal de Tratamento de Resíduos Sólidos; CPGRS: Consórcio Público de Gestão de Resíduos; CORESAB: Consórcio Regional de Saneamento Básico Central de Minas; RSU: Resíduos Sólidos Urbanos.

\section{Avaliação da proposta das rotas tecnológicas para os consórcios}

No caso do Estado de Minas Gerais, as rotas tecnológicas iniciam-se na coleta e terminam na disposição final em aterro sanitário. De outra forma, pode-se dizer que toda e qualquer rota tecnológica tem sempre um sistema de coleta e um aterro sanitário, podendo ter entre estes uma ou mais formas ou tecnologias de tratamento.

Nesta etapa apresentam-se o cenário atual e as rotas tecnológicas encontradas nos seis ATOs; a partir desses dados levantados, foram avaliados os cenários levando-se em conta as propostas nos ATOs, identificando as oportunidades no tratamento dos resíduos que incorporassem o reaproveitamento, a reciclagem e a valorização energética dos resíduos, tendo em vista suas potencialidades econômicas e sociais intrínsecas.

Os consórcios em operação estão inseridos em seis ATOs referenciados no PRE-RSU.

A análise de cada tecnologia é definida segundo o porte dos municípios, estipulado a partir de uma adaptação das faixas intervalares consideradas na elaboração com base na concepção da Secretaria Nacional de Saneamento Ambiental do MMA (GRS/UFPE, 2014).

\section{RESULTADOS E DISCUSSÃO}

\section{Avaliação dos arranjos técnicos, institucionais e legais dos consórcios em operação}

As Tabelas 2 e 3 sintetizam os levantamentos primários realizados nos cinco consórcios em operação e a situação dos municípios em relação ao gerenciamento dos resíduos sólidos na estrutura organizacional e caracterização dos RSU, ao tratamento e à disposição final, conforme dados levantados dos formulários dos cinco consórcios:

- Formulário 1: Avaliação da Estrutura Organizacional;

- Formulário 2: Caracterização dos RSU, do tratamento e da disposição final.

Para cada item de análise, foram previstas três opções de respostas ao atendimento do requisito: $\mathrm{S}$ (atende totalmente), $\mathrm{N}$ (não atende) $\mathrm{e}$ $\mathrm{P}$ (atende parcialmente), correspondentes aos valores 1,0 e pontuadas em relação aos 5 consórcios de 0 a 100\%.

$\mathrm{Na}$ avaliação integrada, em relação ao aspecto legislação ambiental/ apoio jurídico, observou-se que $20 \%$ dos municípios que faziam parte dos consórcios não possuíam plano diretor de resíduos, ou seja, não apresentavam um planejamento das ações relacionadas com a limpeza urbana em curto, médio e longo prazo. Além disso, $40 \%$ dos consórcios estabeleciam políticas e diretrizes relacionadas ao sistema de gestão dos RSU, e em apenas $20 \%$ os serviços de coleta, tratamento e destinação final de resíduos eram prestados diretamente pelo consórcio ou por contratado. 
Tabela 2 - Análise integrada da avaliação da estrutura organizacional dos consórcios.

\begin{tabular}{|c|c|c|c|c|c|c|}
\hline \multirow{2}{*}{ Fator de avaliação } & \multicolumn{3}{|c|}{ Total } & \multicolumn{3}{|c|}{ Total (\%) } \\
\hline & $\mathrm{S}$ & N & $\mathbf{P}$ & $\mathrm{S}$ & $\mathrm{N}$ & $P$ \\
\hline \multicolumn{7}{|l|}{ Legislação ambiental/apoio jurídico } \\
\hline O principal órgão executor das atividades dos consórcios é a Secretaria Executiva? & 4 & 1 & O & 80 & 20 & O \\
\hline Existe plano diretor de resíduos nos municípios? & 2 & 1 & 2 & 40 & 20 & 40 \\
\hline O consórcio estabelece políticas e diretrizes relacionadas ao sistema de gestão dos RSU? & 2 & 1 & 2 & 40 & 20 & 40 \\
\hline $\begin{array}{l}\text { Existem nos municípios e/ou consórcio leis e regulamentos voltados para apoio da } \\
\text { gestão dos resíduos? }\end{array}$ & 3 & 1 & 1 & 60 & 20 & 20 \\
\hline Existe lei municipal de saneamento nos municípios? & O & 3 & 2 & O & 60 & 40 \\
\hline $\begin{array}{l}\text { Como é o estatuto social do consórcio? Prevê prestação de serviço de limpeza urbana } \\
\text { e manejo de RSU? }\end{array}$ & 1 & 3 & 1 & 20 & 60 & 20 \\
\hline $\begin{array}{l}\text { Os serviços de (i) coleta, (ii) transporte, (iii) tratamento e/ou (iv) destinação final de } \\
\text { resíduos são prestados diretamente pelo consórcio ou por contratado? }\end{array}$ & 1 & 3 & 1 & 20 & 60 & 20 \\
\hline Foi firmado algum TAC com o Ministério Público nos municípios? & O & 5 & 0 & 0 & 100 & 0 \\
\hline
\end{tabular}

\section{Estrutura organizacional e alocação de recursos}

Existe um organograma atual do consórcio, com quadro funcional, competência dos diversos órgãos, etc.?

O setor responsável pela gestão dos RSU está alocado em área adequada e favorável dentro do consórcio?

Existe um gestor responsável pelo gerenciamento do setor de RSU?

Existe um departamento específico/assessoria técnica para a gestão ambiental adequadamente estruturada?

O serviço de limpeza urbana é realizado pelo próprio consórcio?

\begin{tabular}{|l|l|l|}
\hline 2 & 3 \\
\hline 2 & 2 \\
\hline 2 & 2 \\
\hline 2 & 3 \\
\hline 0 & 5 \\
\hline
\end{tabular}

\begin{tabular}{|l|}
\hline 0 \\
1 \\
1 \\
0 \\
\hline 0 \\
\hline
\end{tabular}

\begin{tabular}{c|c|c|}
\hline 40 & 60 & 0 \\
\hline 40 & 40 & 20 \\
\hline 40 & 40 & 20 \\
\hline 40 & 60 & 0 \\
\hline 0 & 100 & 0 \\
\hline
\end{tabular}

\section{Política de Recursos Humanos}

Existe programa de treinamento e capacitação dos funcionários do setor administrativo dos RSU?

Programa de segurança e prevenção de acidente é desenvolvido e aplicado no setor? Existe um departamento de Recursos Humanos na área de RSU?

O regime de pessoal é regido pela CLT?

\begin{tabular}{|c|c|c|c|c|c}
\hline 0 & 4 & 1 & 0 & 80 & 20 \\
\hline 0 & 5 & 0 & 0 & 100 & 0 \\
\hline 0 & 5 & 0 & 0 & 100 & 0 \\
\hline 4 & 0 & 1 & 80 & 0 & 20 \\
\hline
\end{tabular}

\section{Gestão financeira e de custos}

\begin{tabular}{|c|c|c|c|c|c|c|}
\hline $\begin{array}{l}\text { Existe sistema estruturado de controle financeiro da renda mensal gerada pelas taxas } \\
\text { de arrecadação dos municípios do consórcio? }\end{array}$ & 2 & 3 & O & 40 & 60 & O \\
\hline $\begin{array}{l}\text { Existe programa de busca de recursos e financiamentos para aplicação no sistema de } \\
\text { gestão dos RSU? }\end{array}$ & 2 & 1 & 2 & 40 & 20 & 40 \\
\hline Existe cobrança da TLP nos municípios dos consórcios? & 2 & 3 & O & 40 & 60 & O \\
\hline E cobrado a coleta dos resíduos? & 0 & 5 & O & 0 & 100 & O \\
\hline Como é feito o repasse de recursos dos municípios para os consórcios? Valor fixo? & 2 & 3 & O & 40 & 60 & O \\
\hline \multicolumn{7}{|l|}{ Requerimento de financiamento das alternativas } \\
\hline Existe algum programa de financiamento para os RSU? & 2 & 1 & 2 & 40 & 20 & 40 \\
\hline \multicolumn{7}{|l|}{ Políticas de inclusão social } \\
\hline $\begin{array}{l}\text { Existe programa de apoio e incentivo para a formação e desenvolvimento de } \\
\text { cooperativas de catadores? }\end{array}$ & 1 & 2 & 2 & 20 & 40 & 40 \\
\hline Existe programa de inclusão social e remuneração para catadores cooperados? & O & 5 & O & 0 & 100 & O \\
\hline \multicolumn{7}{|l|}{ Tecnologia da gestão da qualidade } \\
\hline Capacitação técnica específica sobre resíduos é oferecida aos funcionários do setor? & 2 & 2 & 1 & 40 & 40 & 20 \\
\hline O consórcio aplica os conceitos dos 3R’s na gestão dos resíduos? & 3 & 1 & 1 & 60 & 20 & 20 \\
\hline
\end{tabular}

S: atende totalmente; N: não atende; P: atende parcialmente; TAC: Termo de Ajustamento de Conduta; TLP: taxa de limpeza pública; CLT: Consolidação das Leis do Trabalho; RSU: Resíduos Sólidos Urbanos. 
Em termos de estrutura organizacional e alocação de recursos, 60\% dos municípios com consórcios não apresentavam um organograma funcional que permitisse a identificação da inserção do setor responsável pela gestão dos RSU, 40\% não estavam alocados em área adequada pela gestão dos resíduos e em $40 \%$ não existia um gestor responsável pelo setor de RSU. Em todos os consórcios o serviço de limpeza urbana não era realizado pela própria associação.

Em $80 \%$ dos consórcios não existia um programa de treinamento e capacitação dos funcionários do setor responsável pela gestão dos RSU. Os consórcios, em sua totalidade, não dispunham de um programa de segurança e prevenção de acidentes durante as atividades de coleta, transporte e destinação dos resíduos gerados pelos municípios e de um setor de Recursos Humanos que tratasse somente a área de RSU, e sim de uma única seção que tratava de todos os setores.

A maior parte dos municípios que integram os consórcios (60\%) não apresentava um sistema estruturado de controle financeiro da renda mensal gerada pela taxa de limpeza urbana. De todos os municípios com consórcios, somente $40 \%$ buscavam recursos e financiamentos para aplicação no gerenciamento dos RSU e nenhum dos consórcios fazia a coleta dos RSU.

O Poder Executivo Municipal é responsável pela coleta de resíduos sólidos domiciliares, pelos prestadores de serviços públicos de saneamento e pelas atividades de pequenos comércios. Os serviços públicos na área de resíduos sólidos correspondem à coleta, ao transporte, ao tratamento e à disposição final de resíduos sólidos e à limpeza de vias e logradouros públicos. Observou-se que a maior parte dos municípios que integram os consórcios (60\%) não fazia a cobrança da taxa de limpeza pública (TLP). Os custos adequados, a qualidade e o aumento da oferta são pressupostos para a cobrança dos serviços. Um dos objetivos da PNRS, conforme a Lei no 11.445/2007, no artigo 7, é manter a: "regularidade, continuidade, funcionalidade e universalização da prestação dos serviços públicos de limpeza urbana e do manejo dos resíduos sólidos, com adoção de mecanismos gerenciais e econômicos que assegurem a recuperação dos custos dos serviços prestados,

Tabela 3 - Análise integrada da caracterização dos resíduos sólidos, tratamento e disposição final dos consórcios.

\begin{tabular}{l|l|l|l|c|c|c|}
\multicolumn{3}{|c|}{ Total } & \multicolumn{3}{|c|}{ Total (\%) } \\
\cline { 2 - 6 } Fator de avaliação & $\mathrm{S}$ & $\mathrm{N}$ & $\mathrm{P}$ & $\mathrm{S}$ & $\mathrm{N}$ & $\mathrm{P}$ \\
\hline
\end{tabular}

Caracterização dos resíduos sólidos domiciliares/comerciais

\begin{tabular}{|c|c|c|c|c|c|c|}
\hline Os resíduos são coletados pelo consórcio? & O & 5 & O & O & 100 & O \\
\hline Foi realizada a composição gravimétrica dos resíduos nos municípios dos consórcios? & 4 & 1 & O & 80 & 20 & O \\
\hline A composição gravimétrica é realizada periodicamente? & 1 & 4 & O & 20 & 80 & $\mathrm{O}$ \\
\hline Os municípios apresentam Plano de Gerenciamento de RSU? & 2 & 1 & 2 & 40 & 20 & 40 \\
\hline
\end{tabular}

Coleta Seletiva

\begin{tabular}{l|c|c|c|c|c|c|c|c|}
\hline \multicolumn{1}{|l|}{ Os municípios do consórcio apresentam sistema de coleta seletiva? } & 1 & 1 & 3 & 20 & 20 & 60 \\
\hline A coleta seletiva é feita por associações ou cooperativa de catadores? & 4 & 1 & 0 & 80 & 20 & 0 \\
\hline Unidade de triagem & 1 & 4 & 0 & 20 & 80 & 0 \\
\hline A triagem é feita pelo consórcio? & 0 & 5 & 0 & 0 & 100 & 0 \\
\hline A triagem é feita por empresa terceirizada? & 1 & 4 & 0 & 20 & 80 & 0 \\
\hline A unidade é licenciada?
\end{tabular}

Unidade de compostagem

\begin{tabular}{|c|c|c|c|c|c|c|}
\hline A compostagem é feita pelo consórcio? & 1 & 4 & O & 20 & 80 & $\mathrm{O}$ \\
\hline A compostagem é feita por empresa terceirizada? & O & 5 & O & 0 & 100 & $\mathrm{O}$ \\
\hline A compostagem é licenciada? & 1 & 4 & O & 20 & 80 & O \\
\hline \multicolumn{7}{|l|}{ Tratamento e disposição final dos RSS } \\
\hline Os municípios dos consórcios possuem unidade de tratamento dos RSS? & O & 5 & O & O & 100 & $\mathrm{O}$ \\
\hline O tratamento dos RSS é feito pelo consórcio? & $\mathrm{O}$ & 5 & O & 0 & 100 & $\mathrm{O}$ \\
\hline Existe controle da quantidade de RSS nos municípios do consórcio? & 1 & 4 & O & 20 & 80 & $\mathrm{O}$ \\
\hline \multicolumn{7}{|l|}{ Aterro sanitário } \\
\hline O aterro sanitário do município sede é licenciado? & 4 & 1 & O & 80 & 20 & $\mathrm{O}$ \\
\hline O aterro é operado pelo consórcio? & 4 & 1 & O & 80 & 20 & $\mathrm{O}$ \\
\hline
\end{tabular}

S: atende totalmente; N: não atende; P: atende parcialmente; RSS: resíduos de serviço de saúde. 
como forma de garantir sua sustentabilidade operacional e financeira" (BRASIL, 2007, art. 7, p. 4).

Em $40 \%$ não existe programa de apoio e incentivo para a formação e o desenvolvimento de cooperativas de catadores. Consequentemente, nenhum trabalho de inclusão social foi desenvolvido até o momento em todos os municípios integrantes dos consórcios. Há de se ressaltar que em $89 \%$ dos consórcios não são oferecidos cursos de formação para os cooperados.

Com relação à tecnologia de gestão de qualidade, em $40 \%$ dos consórcios é oferecida a capacitação técnica específica aos funcionários envolvidos no gerenciamento dos RSU; já em $60 \%$ dos municípios os funcionários não são capacitados para a aplicação dos conceitos de redução, reutilização e reciclagem de resíduos (3 Rs). Esse resultado indica o baixo investimento dos consórcios nessa área de gestão.

A Figura 2 sintetiza uma análise integrada referente à situação da estrutura organizacional dos cinco consórcios em relação ao gerenciamento dos RSU.

Quanto à estrutura organizacional dos consórcios em relação ao gerenciamento dos RSU, verificou-se que, em média, $50 \%$ não apresentavam um sistema adequado. $\mathrm{O}$ valor indica as deficiências e os aspectos institucionais desfavoráveis apresentados pelos consórcios em relação às questões ligadas ao planejamento do sistema e à tecnologia de gestão, à legislação ambiental, à estrutura organizacional, à alocação de recursos, às questões financeiras e de custos, aos Recursos Humanos e à capacitação dos funcionários, à inclusão social e ao apoio à cooperativa de catadores.

Quando analisada a situação da estrutura organizacional, foram encontradas fragilidades comuns em todos os fatores de avaliação em relação ao gerenciamento dos RSU. Para atender à estrutura organizacional dos consórcios, os municípios devem buscar as necessidades organizacionais referentes ao seu planejamento, ampliando, assim, a oferta de serviços em todos os aspectos (financeiros, de Recursos Humanos, sociais e administrativos),

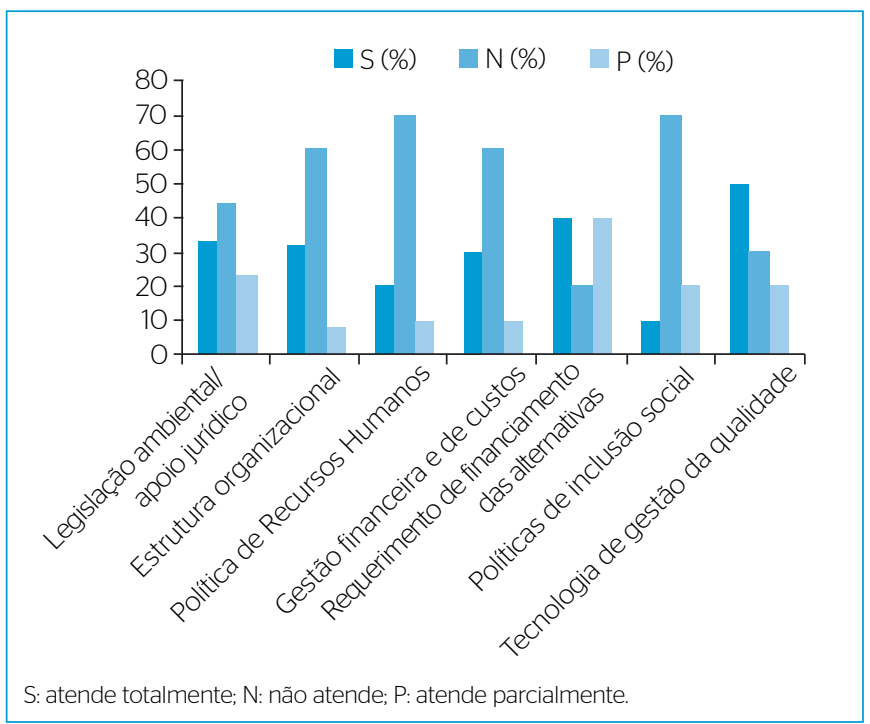

Figura 2 - Análise integrada referente à situação da estrutura organizacional dos consórcios. assim como atender às necessidades impostas pelas peculiaridades e capacidades locais dos municípios integrantes dos consórcios.

Em relação aos aspectos de caracterização dos resíduos sólidos, do tratamento e da disposição final, em 80\% dos municípios com consórcios foram realizados trabalhos de determinação da composição gravimétrica dos resíduos gerados, ou seja, os municípios conhecem o percentual de cada componente presente em uma massa de resíduo, o que possibilita avaliar o potencial de reciclagem dos componentes e seu melhor gerenciamento; em apenas $20 \%$ dos municípios a composição gravimétrica é realizada periodicamente. Nota-se a fragilidade dos municípios, pois a caracterização qualiquantitativa dos RSU é um importante instrumento de planejamento para os consórcios. Além de oferecer subsídios à formulação dos programas de coleta seletiva, também é importante para o cálculo dos parâmetros que serão utilizados no projeto de tratamento e disposição final. Dos municípios integrantes dos consórcios, 40\% apresentam Plano de Gerenciamento de RSU.

Até o momento, a implantação de sistema de coleta seletiva efetiva foi desenvolvida em apenas $20 \%$ dos municípios (os mesmos que apresentam UTC em operação).

Nota-se um quadro alarmante com relação aos resíduos do serviço de saúde (RSS): nenhum dos municípios dos consórcios possui unidade de tratamento de RSS e somente $20 \%$ têm controle da quantidade de RSS; nenhum dos consórcios realiza o tratamento dos RSS.

Todos os consórcios dispõem seus RSU em aterros sanitários licenciados, exceto o Consórcio Intermunicipal de Reciclagem e Compostagem do Lixo, que possui uma UTC licenciada.

A Figura 3 sintetiza uma análise integrada referente à situação da caracterização dos RSU, do tratamento e da disposição final dos cinco consórcios.

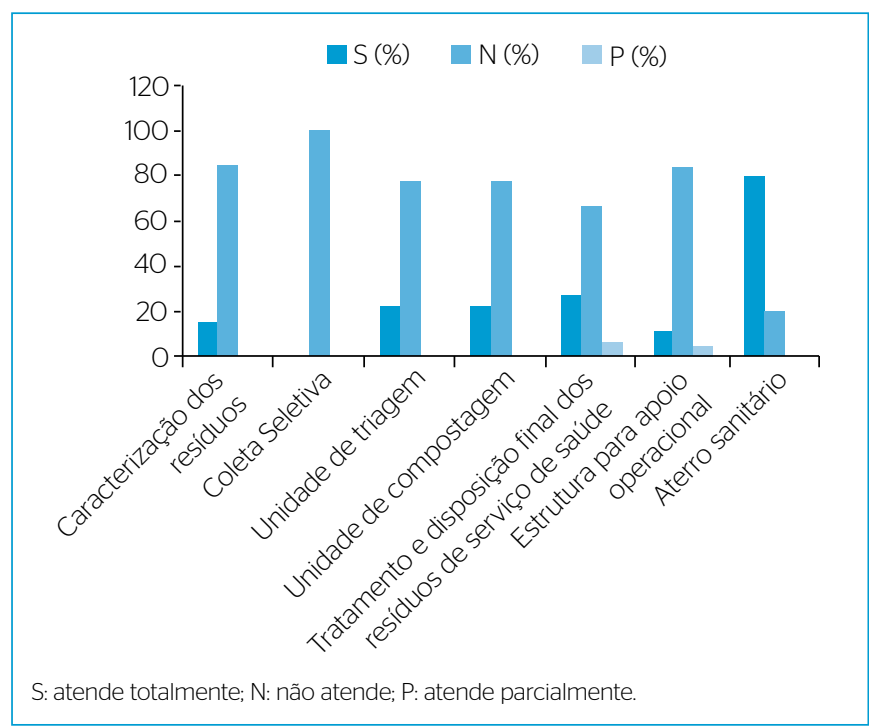

Figura 3 - Análise integrada da caracterização dos resíduos sólidos, tratamento e disposição final dos consórcios. 
O resultado demonstra que, para todos os fatores avaliados referentes à caracterização dos resíduos, do tratamento e da disposição final, 73\% dos municípios integrantes dos consórcios não apresentam um sistema adequado. $\mathrm{O}$ valor indica que, de uma maneira geral, não está sendo realizado o processo de gestão de RSU, o que evidencia as deficiências e carências do sistema nos municípios que fazem parte dos consórcios.

\section{Avaliação da proposta das rotas tecnológicas para os consórcios}

Uma das variáveis importantes a considerar para a tomada de decisão sobre rotas tecnológicas adequadas é o tamanho da população atendida. Soluções ou rotas tecnológicas adequadas para grandes cidades podem não ser as mesmas para pequenas e médias comunidades; ou ainda, tecnologias não viáveis para pequenas cidades podem passar a ter viabilidade quando soluções associadas forem adotadas.

Os dados utilizados basearam-se no Projeto GRS/FADE/UFPE/BNDES e nas indicações da FEAM (2012) sobre os municípios que estavam realizando adequadamente o tratamento e a destinação final dos RSU no Estado.

A avaliação da proposição para os ATOs considerou a base das faixas populacionais (Tabela 4).

Os consórcios em operação estão inseridos em seis ATOs. A Tabela 5 apresenta a proposição das rotas tecnológicas baseadas nas faixas populacionais e das rotas tecnológicas para os ATOs (Tabela 4).

Observou-se que para os consórcios em operação inseridos nos seis ATOs existe um número considerável de municípios com população entre 250.000 e 1.000.000 habitantes, e que a rota tecnológica 3 se impõe como tendência, visto que propõe coleta diferenciada e indiferenciada de resíduos, transporte e encaminhamento dos rejeitos para a unidades de tratamento e disposição final de RSU.

Para o ATO Curvelo e Bocaiúva, a rota tecnológica 2 se impõe como tendência, pois propõe coleta domiciliar de rejeitos, coleta diferenciada de resíduos recicláveis e de resíduos orgânicos de grandes geradores, transporte, unidades de triagem para destinação dos resíduos recicláveis secos e encaminhamento dos rejeitos para aterros sanitários.
Tabela 4 - Proposição referente às faixas populacionais e rotas tecnológicas para os Arranjos Territoriais Ótimos.

\begin{tabular}{|c|c|c|}
\hline $\begin{array}{l}\text { Faixas } \\
\text { populacionais }\end{array}$ & Rotas tecnológicas & Código \\
\hline$<30.000$ & $\begin{array}{l}\text { Coleta domiciliar de resíduos não recicláveis, } \\
\text { coleta de resíduos recicláveis secos, } \\
\text { transporte e disposição dos resíduos não } \\
\text { recicláveis em aterros sanitários. }\end{array}$ & 1 \\
\hline $\begin{array}{l}30.001 \text { a } \\
250.000\end{array}$ & $\begin{array}{l}\text { Coleta domiciliar de rejeitos (resíduos não } \\
\text { recicláveis), coleta diferenciada de resíduos } \\
\text { recicláveis, coleta diferenciada de resíduos } \\
\text { orgânicos de grandes geradores, transporte, } \\
\text { unidades de triagem para destinação dos } \\
\text { resíduos recicláveis secos e disposição dos } \\
\text { rejeitos em aterros sanitários. } \\
\text { Os recicláveis são destinados a uma } \\
\text { Central de Triagem mais bem estruturada } \\
\text { e adequada a uma maior quantidade de } \\
\text { materiais a serem triados. } \\
\text { O transporte poderá incluir, a depender } \\
\text { das distâncias, estações de transbordo que } \\
\text { reduzem os custos do sistema. } \\
\text { Esta rota tecnológica já considera a } \\
\text { produção de composto a partir da coleta } \\
\text { diferenciada de matéria orgânica de grandes } \\
\text { geradores. Os quantitativos de resíduos para } \\
\text { essa faixa de população ainda não permitem } \\
\text { a inclusão do aproveitamento enérgico no } \\
\text { aterro sanitário, mas viabilizam, a custos } \\
\text { razoáveis, a construção e a operação de } \\
\text { aterros com boa qualidade técnica. }\end{array}$ & 2 \\
\hline $\begin{array}{l}250.001 \mathrm{a} \\
1.000 .000\end{array}$ & $\begin{array}{l}\text { Coleta diferenciada e indiferenciada de resíduos, } \\
\text { transporte e encaminhamento a unidades de } \\
\text { tratamento e disposição final de RSU, tais como } \\
\text { compostagem, reciclagem e aterros sanitários } \\
\text { sendo possível para municípios deste porte, } \\
\text { considerar a possibilidade de aproveitamento } \\
\text { energético do gás em algumas regiões. } \\
\text { A consideração de unidades de transbordo } \\
\text { poderá viabilizar as operações em municípios } \\
\text { com distâncias superiores a } 25 \text { km entre as } \\
\text { áreas de coleta e o local de disposição final. }\end{array}$ & 3 \\
\hline$>1.000 .000$ & $\begin{array}{l}\text { Coleta diferenciada de recicláveis (secos) e } \\
\text { orgânicos (úmidos), coleta de resíduos não } \\
\text { recicláveis, triagem, transbordo, compostagem e } \\
\text { aterro sanitário com aproveitamento energético. } \\
\text { Os catadores de materiais recicláveis, em } \\
\text { número bem mais expressivo, deverão ser } \\
\text { acompanhados de forma sistemática pelos } \\
\text { municípios e entidades de apoio à gestão. }\end{array}$ & 4 \\
\hline
\end{tabular}

Fonte: adaptado de GRS/UFPE (2014).

Tabela 5 - Proposição das Rotas tecnológicas para os Arranjos Territoriais Ótimos.

\begin{tabular}{l|c|c|c|c|c|c}
\multirow{2}{*}{ ATOs } & \multirow{2}{*}{$\begin{array}{c}\text { População } \\
\text { total (2010) }\end{array}$} & \multicolumn{2}{|c|}{$\begin{array}{c}\text { Cenário atual } \\
\text { (FEAM, 2012) }\end{array}$} & $\begin{array}{c}\text { Faixas populacionais } \\
\text { e rotas tecnológicas }\end{array}$ \\
\cline { 5 - 7 } & & & Lixão & AC & $\begin{array}{c}\text { AS e UTC } \\
\text { Regularizado }\end{array}$ & (Código, Tabela 4) \\
\hline Conselheiro Lafaiete & 23 & 313.208 & 7 & 3 & 13 & 3 \\
\hline Itabira & 18 & 348.185 & 2 & 9 & 7 & 3 \\
\hline Itajubá & 32 & 399.219 & 12 & 10 & 10 & 3 \\
\hline Curvelo & 17 & 241.968 & 8 & 6 & 3 & 3 \\
\hline Sete Lagoas & 22 & 587.993 & 5 & 6 & 11 & \\
\hline Bocaiúva & 8 & 84.088 & 5 & 3 & & 3 \\
\hline
\end{tabular}

ATOS: Arranjos Territoriais Ótimos; AC: aterro controlado; AS: aterro sanitário; UTC: unidade de triagem e compostagem. 
A Tabela 6 apresenta a avaliação da proposição das rotas tecnológicas para os consórcios em operação inseridos nos seis ATOs.

Para os consórcios em operação existe um número considerável de municípios com população entre 30.001 e 250.000 habitantes, e para a proposição das rotas tecnológicas prevalece a rota tecnológica 2. Porém, o que se observa é a coleta convencional/aterro controlado e/ou aterro sanitário. Uma segunda rota a ser considerada nos consórcios inclui UTC pós-coleta, principalmente para municípios de pequeno porte, como o Consórcio Intermunicipal de Reciclagem e Compostagem de Lixo. Observa-se que no Consórcio Público Intermunicipal de Tratamento de Resíduos Sólidos (ECOTRES) e no Consórcio Regional de Saneamento Básico Central de Minas (CORESAB) ainda há a presença de lixões.

As tecnologias de tratamento devem ser complementares, não sendo recomendada a proposição ou implantação de tecnologias que não se complementem, mesmo que sejam recomendáveis individualmente.

Tabela 6 - Avaliação da proposição das rotas tecnológicas dos consórcios.

\begin{tabular}{|c|c|c|c|c|c|c|}
\hline ATOs & $\begin{array}{l}\text { Consórcios } \\
\text { "em operação" }\end{array}$ & Municípios & $\begin{array}{l}\text { População } \\
\text { total, em } \\
\text { habitantes } \\
(2010)\end{array}$ & $\begin{array}{l}\text { Cenário atual } \\
\text { (FEAM, 2012) }\end{array}$ & $\begin{array}{l}\text { Coleta } \\
\text { seletiva } \\
\text { (FEAM, } \\
\text { 2013) }\end{array}$ & $\begin{array}{l}\text { Faixas populacionais e } \\
\text { rotas tecnológicas } \\
\text { (Código, } \\
\text { Tabela 4) }\end{array}$ \\
\hline \multirow{8}{*}{$\begin{array}{l}\text { ATO } \\
\text { Conselheiro } \\
\text { Lafaiete }\end{array}$} & \multirow{5}{*}{$\begin{array}{c}\text { Consórcio } \\
\text { Intermunicipal } \\
\text { de Reciclagem e } \\
\text { Compostagem do Lixo }\end{array}$} & Queluzito & \multirow{5}{*}{16.222} & UTC regularizada & Sim & \multirow{5}{*}{1} \\
\hline & & Cristiano Otoni & & UTC regularizada & & \\
\hline & & Caranaíba & & UTC regularizada & $\operatorname{Sim}$ & \\
\hline & & Casa Grande & & UTC regularizada & Sim & \\
\hline & & Santana dos Montes & & UTC regularizada & & \\
\hline & \multirow{3}{*}{ ECOTRES } & Ouro Branco & \multirow{3}{*}{200.299} & Lixão & & \multirow{3}{*}{2} \\
\hline & & Congonhas & & Lixão & & \\
\hline & & Conselheiro Lafaiete & & Lixão & & \\
\hline \multirow{5}{*}{$\begin{array}{l}\text { ATO } \\
\text { Itabira }\end{array}$} & \multirow{5}{*}{$\begin{array}{l}\text { Consórcio Público de } \\
\text { Gestão de Resíduos }\end{array}$} & Bela Vista de Minas & \multirow{5}{*}{130.552} & AS não regularizado & & \multirow{5}{*}{2} \\
\hline & & João Monlevade & & AS não regularizado & Sim & \\
\hline & & Rio Piracicaba & & AS não regularizado & & \\
\hline & & Nova Era & & AS não regularizado & Sim & \\
\hline & & Alvinópolis & & AS não regularizado & & \\
\hline \multirow{6}{*}{$\begin{array}{l}\text { ATO } \\
\text { Itajubá }\end{array}$} & \multirow{6}{*}{ CIMASAS } & Delfim Moreira & \multirow{6}{*}{118.411} & AS regularizado & & \multirow{6}{*}{2} \\
\hline & & Itajubá & & AS regularizado & Sim & \\
\hline & & Piranguinho & & AS regularizado & $\operatorname{Sim}$ & \\
\hline & & Piranguçu & & AS regularizado & Sim & \\
\hline & & São José do Alegre & & AS regularizado & & \\
\hline & & Wenceslau Brás & & AS regularizado & & \\
\hline \multirow{18}{*}{$\begin{array}{l}\text { ATO } \\
\text { Curvelo, ATO } \\
\text { Sete Lagoas e } \\
\text { ATO Bocaiúva }\end{array}$} & \multirow{18}{*}{ CORESAB } & Três Marias & \multirow{18}{*}{239.948} & $A C$ & & \multirow{18}{*}{2} \\
\hline & & Monjolos & & Lixão & & \\
\hline & & Santo Hipólito & & Lixão & & \\
\hline & & Corinto & & Lixão & & \\
\hline & & Morro da Garça & & AS regularizado & & \\
\hline & & Curvelo & & AS regularizado & $\operatorname{Sim}$ & \\
\hline & & Felixlândia & & Lixão & Sim & \\
\hline & & Inimutaba & & AS regularizado & & \\
\hline & & Datas & & Lixão & & \\
\hline & & Gouveia & & Lixão & & \\
\hline & & Araçai & & $A C$ & & \\
\hline & & Cordisburgo & & $A C$ & & \\
\hline & & Paraopeba & & Lixão & Sim & \\
\hline & & Presidente Juscelino & & $A C$ & & \\
\hline & & Lassance & & Lixão & Sim & \\
\hline & & Santana de Pirapama & & $A C$ & & \\
\hline & & Buenópolis & & Lixão & & \\
\hline & & Augusto de Lima & & $A C$ & & \\
\hline
\end{tabular}

ATO: Arranjo Territorial Ótimo; AC: aterro controlado; AS: aterro sanitário; UTC: Unidade de Triagem e Compostagem; CIMASAS: Consórcio Intermunicipal de municípios do Alto Sapucaí para Aterro Sanitário; ECOTRES: Consórcio Público Intermunicipal de Tratamento de Resíduos Sólidos; CPGRS: Consórcio Público de Gestão de Resíduos; CORESAB: Consórcio Regional de Saneamento Básico Central de Minas. 
A inserção das cooperativas de catadores no processo de gestão dos RSU também deverá ser abordada, assim como a possibilidade de reciclagem da matéria orgânica a partir de tecnologias de compostagem, sendo que uma rota de compostagem pressupõe uma etapa prévia de coleta de material pré-selecionado.

Ressalta-se que a garantia de uma gestão eficiente de RSU requer ainda que se estabeleçam mecanismos de conscientização da população, bem como políticas e ações de educação ambiental.

Cabe destacar que a análise das proposições é um indicativo de possibilidades, não substituindo a necessidade de elaboração de estudos de viabilidade técnica e econômica para cada tecnologia específica.

\section{CONCLUSÕES}

O artigo contribui para a avaliação dos consórcios públicos em operação como uma alternativa no campo da gestão de RSU atendendo a um maior número de municípios, de modo que viabiliza a gestão dos RSU com o objetivo de fortalecer os consórcios, ampliando a sua importância, representatividade e abrangência.

É preciso estar atento para as possibilidades, além das normas, pois a proposta para o consórcio pode ser uma importante ferramenta de gestão e planejamento dos RSU, e essa escolha cabe aos prefeitos. Essa união possibilita ainda a identificação de características socioeconômicas, culturais e estruturais dos entes consorciados, o que permitiria a definição de estratégias comuns para a promoção do crescimento em conjunto. Os prefeitos, desde que alinhados, são capazes de encontrar soluções conjuntas para o desenvolvimento e devem estar atentos para o fato de as mudanças socioeconômicas, como outras tantas, serem capazes de alterar o cenário dos resíduos.

Aos municípios componentes do consórcio compete o alinhamento das prioridades, dos investimentos e do planejamento para a consecução de um modelo voltado às situações que afetam uma comunidade circunvizinha. O poder municipal, no que se refere à adesão pela operacionalização desse serviço, precisa ter uma visão estratégica de interesse em resolver de forma conjunta/consorciada o tratamento e a destinação final dos RSU abordando as rotas tecnológicas e considerando os aspectos sociais, econômicos e ambientais da realidade local.

\section{AGRADECIMENTOS}

Os autores agradecem ao CNPq pela bolsa de Pós Doutorado concedida para esta pesquisa, ao Grupo de Resíduos Sólidos da Universidade Federal de Pernambuco (GRS/UFPE) e a Fundação Estadual do Meio Ambiente (FEAM), notadamente aos técnicos da DGER.

\section{REFERÊNCIAS}

BRASIL. (2005) Lei no 11.107, de 06 de abril de 2005. Dispõe sobre normas gerais de contratação de consórcios públicos e dá outras providências. Disponível em: <www.planalto.gov.br/legislacao>. Acesso em: 20 jan. 2015.

BRASIL. (2007) Lei no 11.445, de 05 de janeiro de 2007. Estabelece diretrizes nacionais para o saneamento básico. Disponível em: <www.planalto.gov.br/legislacao> Acesso em: 20 jan. 2015.

BRASIL. (2010) Lei no 12.305, de O2 de agosto de 2010. Institui a Política Nacional de Resíduos Sólidos Urbanos. Disponível em: <www.planalto.gov.br/legislacao>. Acesso em: 20 jan. 2015.

FERREIRA, C.F.A.; ROCHA G.H.T; MYSSIOR, S.; FONSECA, F.P. (2010) Proposta do plano de regionalização de Minas Gerais para a gestão integrada dos resíduos sólidos urbanos. In: Simpósio Italo Brasileiro de Engenharia Sanitária e Ambiental, 10 Anais... Maceió: ABES.

FEAM - FUNDAÇÃO ESTADUAL DO MEIO AMBIENTE. (2012) Situação do tratamento e disposição final dos RSU de Minas Gerais em 2012. Belo Horizonte: FEAM. Disponível em: <www.feam.br/ minas_sem_lixões>. Acesso em: 10 fev. 2014.
GRS/UFPE - GRUPO DE RESÍDUOS SÓLIDOS DA UNIVERSIDADE FEDERAL DE PERNAMBUCO. (2014) Análise das diversas tecnologias de tratamento e disposição final de resíduos sólidos urbanos no Brasil, Europa, Japão e Estados Unidos (Projeto GRS/FADE/UFPE/BNDES). Recife: GRS/UFPE. Disponível em: <http: www.tecnologiaresiduos.com.br>. Acesso em: 10 ago. 2014

MINAS GERAIS. (2008) Deliberação Normativa COPAM no 118, de 27 de julho de 2008. Altera os artigos $2^{\circ}, 3^{\circ}$ e $4^{\circ}$ da Deliberação Normativa 52/2001, estabelece novas diretrizes para adequação da disposição final de resíduos sólidos urbanos no Estado, e dá outras providências. Belo Horizonte: FEAM.

MINAS GERAIS. (2009) Lei no 18.031, de 12 de janeiro de 2009. Dispõe sobre a Política Estadual dos Resíduos Sólidos. Disponível em: <www.almg.gov.br/legislacao>. Acesso em: 20 jan. 2014.

SEDRU - SECRETARIA DO ESTADO DE DESENVOLVIMENTO REGIONAL E POLÍTICA URBANA. (2013) Relatório sobre consórcios públicos para gestão integrada de resíduos sólidos acompanhados pela SEDRU. Belo Horizonte: SEDRU. 